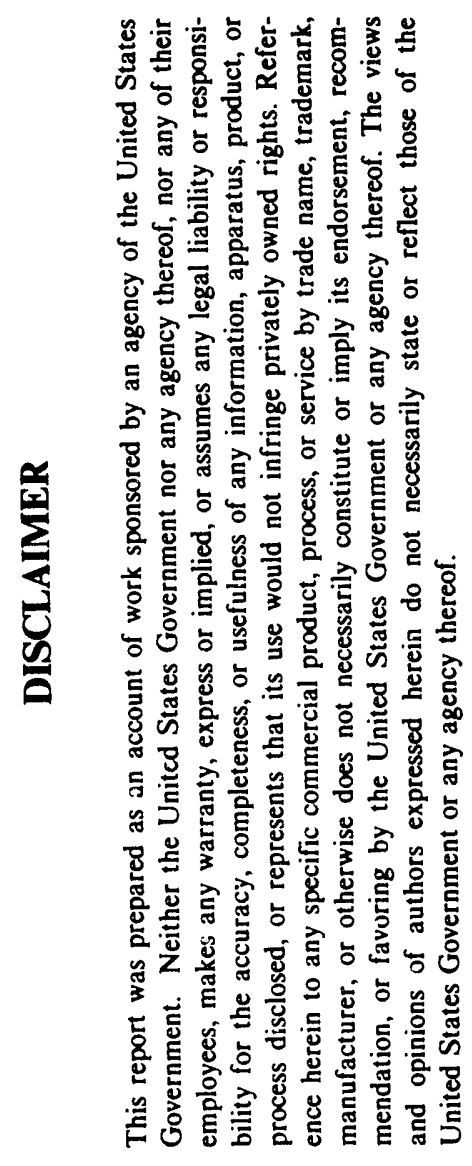

\title{
ISOTOPE SEPARATION SYSTEM EXPERIMENTS AT THE TSTA
}

M. Inoue, S. Konishi, T. Yamanishi, S. Ohira, T. Watanabe, K. Okuno and $Y$. Naruse Japan Atomic Energy Research Institute

R. H. Sherman, J. W. Barnes, J. R. Bartlit, J. L. Anderson Tritium Science and Technology Group Materials Science and Technology Division:

Fourth Topical Meeting on Tritium Technology in Fission, Fusion, and Isotopic Applications sponsored by the Los Alamos National Laboratory

Albuquerque, New Mexico

29 September - 4 October 1991 


\title{
ISOTOPE SEPARATION SYSTEM EXPERIMENTS AT THE TSTA
}

\author{
M. Inoue, S. Konishi, T. Yamanishi, S. Ohira, T. Watanabe, K. Okuno \\ and $Y$. Naruse \\ Japan Atomic Energy Research Institute
}

R. H. Sherman, J. W. Barnes, J. R. Bartlit and J. L. Anderson Los Alamos National Laboratory

\begin{abstract}
ABSTRUCT
The recent results of the Isotope separation Sistem (ISS) operations at the Tritium Systems Test Assembly (TSTA) with $100 \mathrm{~g}$ of tritium indicate that the system generally satisfies design goals, while system stability problems remain to be solved. We configured the Iss system for the three column mode to eliminate such instability and operated it for six days. Fluctuations in flows and liquid levels were improved. Column separation characteristics obtained were satisfactory and agreed with the numerical analysis. The amount of discharged tritium was an acceptable effluent level. This means that the existing Iss system can be used as a three column system and possibly be applied to numerous fuel concepts. Presently, a new laser Raman spectroscopic gas analyzer has been installed at the ISS. This on-line system enables studies of the ISS dynamic behavior for further stability and performance data.
\end{abstract}

\section{INTRODUCTION}

The ISS at the TSTA consisting of four interlinked cryogenic distillation columns - - Columns I, H, D and T - processes hydrogen isotopes at $15 \mathrm{~mol} / \mathrm{hr}$. This four-column system is designed to produce four product streans, namely: an essentially tritium free hydrogen stream from Column $\mathrm{H}$, a high-purity $\mathrm{D}_{2}$ stream from Column $\mathrm{D}$, a stream simulates refuelling and plasma heating by a neutral beam injection, a stream of basically pure DT stream for refueling from Column $D$ and $T$, and a high-purity $\mathrm{T}_{2}$ stream from column $\mathrm{T}^{1,2}$. In recent years, a number of long-term ISS operations have been performed safely with $100 \mathrm{~g}$ of tritium to establish a fusion fuel processing technology on a practical scale under the collaborative program between US/DOE and Japan Atomic Energy Research Institute (JAERI)3,4,5,6. 19 days long of continuous operational period has been marked in $1989^{7}$. In the meanwhile, the single and two column cascade experiments have been held to study individual basic characteristic and operational parameters for each column, such as the Height Equivalent to a Theoretical Plate (HETP), the liquid holdup, the reflux ratio and vapor velocities and pressure drops within the columns, under various operational conditions $8,9,10$.

These results indicate that the system generally satisfies design parameters and goals, while system stability problems remain to be solved. The instabilities seems to come mainly from fluctuations of system flow and liquid level at the reboiler, and possibly dynamic behaviors peculiar to a multicolumn cascade system. A reduction of the number of columns, namely reduction of number of controlled items, is a possible solution to eliminate such instability. Highly purified DT or T2 streams may not be necessary in some future fusion fuel cycle designs. The 3 column run was held in october, 1990, and has been 
performed continuously for 6 days. The present study provides discussions and latest knowledges for further system stability and separation characteristics concerning some significant operational factors, and the precursory considerations for dynamic analysis with a promising on-line gas analyzing system.

\section{EXPERTMENTAI}

We configured the ISS system for the three column mode with Column $I, H$ and $D$ by arranging $a$ loop path as shown in Fig. 1 . Column $T$ had flow here, but was kept at liquid nitrogen temperature without cooling the condenser and packing by the helium refrigerator. The products from Column $D$ and the bottom of Column $I$ were sent to the cryogenic molecular sieve beds of the Fuel Clean-Up Unit (FCU) to eliminate impurities which may cause cryogenic plugs, and pumped to the inlet of the leading column I by the Transfer fumping Unit (TPU) system. Some of $D_{2}$ rich flow from Column $D$ were recycled to the feed of Column H. This flow simulates a disposal $D_{2}$ stream from a neutral beam injection (NBI) system. $\mathrm{H}_{2}$ was added to the system continuously as an impurity from the Impurity Makeup System (IMS) in order to enhance removal of He on Column $H$. The waste gas, which contains mainly $3 \mathrm{He}, \mathrm{H}_{2}$ and $\mathrm{HD}$, off Column $\mathrm{H}$ top was continuously monitored its tritium level by an ion chamber. For final cleanup before disposal, it was dumped to the Tritium Waste Treatment (TWT) system at flow rates of 100 or $260 \mathrm{~cm} 3 / \mathrm{min}$. The two catalytic room-temperature isotopic equilibrators promote the reversible reaction: $\mathrm{HT}+\mathrm{D}_{2}=\mathrm{HD}+\mathrm{DT}$. Thus, the reactors diminish undesirable HT molecules at the feed of Column $H$ and $D$. The nominal operation conditions and the column dimensions are listed in Table 1.

The columns were cooled from room temperature with filling liquid $\mathrm{N}_{2}$ into the jacket of primary containment walls and the helium refrigerator. Additionally the He refrigerator cooled them to the temperature that hydrogen isotopes would condense. The system was initially loaded with a hydrogen isotopes mixture of $10 \mathrm{~g} \mathrm{~mol} \mathrm{H}, 243 \mathrm{~g}$ mol $\mathrm{D}$ and $84 \mathrm{~g}$ mol $\mathrm{T}$ (isotopic ratio: $\mathrm{H}: \mathrm{D}: \mathrm{T}=0.030: 0.721: 0.249$ ) from the four uranium beds heated to $450{ }^{\circ} \mathrm{C}$ in the Uranium Tritide Beds (UTB) system.

During the run, gas samples were periodically withdrawn from various position along columns for analysis by the gas chromatographies (GC). The two GC systems, which consist of both thermal conductivity and ion chamber detectors, employ 5A molecular sieve columns with $\mathrm{Fe}_{2} \mathrm{O}_{3}$ coating and cooled at liquid $\mathrm{N}_{2}$ temperature. Neon was used as a carrier gas. The GCs analyzed column composition profiles and internal diagnostics for system control alternately while varying operating conditions. The Master Data Acquisition and Control (MDAC) system archived all column variables every minute and controlled process variables, valve positions and components/instruments in the system.

\section{BESUITS AND DISCUSSION}

\section{A. System stability}

Most of the operation time was spent to achieve steady state operation. A satisfactory stable operation has been established for last 26 hours. Then the fluctuations in flows and liquid levels were 
improved for Column I and $H$, while Column $D$ had less improvement due to instrument problems. Neither flooding nor loading was observed throughout the run. Fig 2. shows the relation between the measured pressure drops across the columns and the vapor velocities for Column I and $H$ during the run. The relationship provides an useful aspect of columns in operation for evaluating system stability. vapor velocities were calculated from GC analysis data, calories applied to the reboiler of columns and other measured process values. For reference, the identical data for Column $I$ and $T$ obtained in the past 4 column configuration run and the total recycle experiments of column $I$ and $T$ with D-T mixture are also plotted here ${ }^{10}$. The present results, in general, correspond to the consequences obtained in past works $8,9,10$ that the pressure drop are roughly proportional to the vapor velocity to the power. These also indicate that the columns has been in proper operational condition.

An effect of reduction of column $T$ can be found in lowered pressure drops of Column I. In the 4 column runs, turbulence of the recycle flow from column $T$ has affected the feed flow and liquid within Column $I$ and might generate liquid channeling or stagnation which promotes pressure drop increasing. Higher pressure drops of Column $T$ in the 4 column run, in comparison with those of the total recycle mode, suggests that the severe disturbance may have occurred within Column $T$ as well. Column $\mathrm{H}$ has highest pressure drops and a steepest slope in the rectilinear interrelation on Fig. 2. The slope value, $i$. $e$. proportional power coefficient of vapor velocity, for Column $H$ is 2.2 or more while those of Column $I$ and $T$ in total recycle mode are 1.1 and 1.3 respectively. One possible reason for this is fluctuation of the recycle flow from Column $D$ which has been observed during the run due to flow control problem. Another is difference of packed section dimensions, especially inner diameters, among the columns as listed on Table 1 .

\section{B. General separation characteristics}

The computer steady state simulation codes for the cryogenic distillation column with a tridiagonal matrix method has been developed by the JAERI ${ }^{8,9}$. The code calculates the composition distribution with measured feed compositions and numerous measured variables. A modeling with a constant HETP value of $5 \mathrm{~cm}$ along the columns was assumed in analyses. The GC analyses were concentrated on Column $I$ and $H$ because of restricted GC availability and operation time. Fig. 3 and 4 show the calculated gaseous composition profiles for Column I and H respectively. Both GC data for Column I and $H$ plotted on the figure have been sampled and analyzed at almost same time, and generally agree with the numerical analyses. Column I seems to have fully established a steady state condition and produced $40 \%$ of DT and $60 \%$ of $\mathrm{D}_{2}$ streams from the bottom as designed. The GC data of column $H$ has poorer agreements within the column which were experienced in the past operations ${ }^{5}$. However, better conformities can be seen in the top and bottom product compositions and small quantity elements such as HT. These issues may be ascribed to dynamic disproportions of the system due to continuous discharging from the top. Hydraulic effects; liquid flow turbulences or higher pressure drops described above, on material transportations within the column might also concern. For further understanding, dynamic study and/or considerations for nonlinearity of distillation mechanism along a column should be coricerned. 
The amount of tritium off the top of Column $H$ during the run, which was estimated by integrating the measurements of the ion chamber, was about $100 \mathrm{mci}$. This amount is an acceptable effluent level to the TWT. No active control has been made for Column $D$ due to instrument problems, whereas the $D_{2}$ production with purity of more than $98 \%$ from the top has been identified on GC analyses. After the operation, all hydrogen isotopes in the system were unloaded to the UTB system and checked the composition by an off-line mass spectrometer as a sitespecific inventory control task. Recovered hydrogen isotopes were $21 \mathrm{~g}$ mol $\mathrm{H}, 280 \mathrm{~g} \mathrm{~mol} \mathrm{D}$ and $84 \mathrm{~g}$ mol $\mathrm{T}$. The difference of quantities from the initially loaded met with additional $\mathrm{D}_{2}$ and $\mathrm{H}_{2}$ amount during the run which are described in the later section.

These results imply that the 3 column configuration provided quite equivalent or better $D_{2} / D T$ production performance than that with 4 columns, and the numerical assumption: an uniform HETP value of $5 \mathrm{~cm}$ along the columns, is expedient as reported in the other works $5,8,9,10$.

\section{Response to parameter changes}

Fig. 5 gives the internal $\mathrm{H}_{2}$ and HD composition profiles of Column $H$ when varying the withdrawal top flow rate from $100 \mathrm{cc} / \mathrm{min}$ to $260 \mathrm{cc} / \mathrm{min}$. The system variables including feed composition were almost same between these two cases. Poorer agreements with measured values are observed again except at the top and bottom. Both cases show that $\mathrm{H}_{2}$ and HD were dominant components in Column $H$ and externally fed hydrogen was accumulated there. HT amount off the top was extremely few in each case. Meanwhile the light key, $\mathrm{H}_{2}$ and $\mathrm{HD}$, profiles are drastically different and contrary between the two. This means that the top withdrawal flow rate, i.e. reflux ratio (vapor flow rate / top withdrawn flow rate - 1.0$)$ is quite sensitive to the column distillation characteristics and increasing the top flow rate deteriorates separation performance. The computational parameter survey may substantiate the tendency. Fig. 6 shows calculated $\mathrm{H}_{2}$, $\mathrm{HD}$ and $\mathrm{D}_{2}$ composition changes at the top when varying the reflux ratio of 198 to 3.4 which equivalents to variation of the top flow rate between 100 to $4500 \mathrm{cc} / \mathrm{min}$. The other system process data and feed composition used were same as measured in the above $100 \mathrm{cc} / \mathrm{min}$. case and fixed through the calculations. The result shows remarkable dependence of reflux ratio on protium elements separation of Column $\mathrm{H}$. $\mathrm{H}_{2}$ composition changes proportionately to reflux ratio and gets $100 \%$ at reflux ratio of 180 . HD is also increases proportionately in lower reflux ratio region. However, it decreases inversely in the reflux ratio between 16 and 198; the top flow rate of 1200 to $100 \mathrm{cc} / \mathrm{min}$. , after $\mathrm{D}_{2}$ disappears. Hence slight flow perturbation at the top rises an intense excursion of the system from stable condition in higher reflux ratio region, and may prevent the column from getting steady state. This characteristic suggests another possible reason for the poor agreement of measurements for Column $\mathrm{H}$.

In the end of the run, we introduced $D_{2}$. into the system to investigate a system response due to a step fluctuation of system inlet load. $\mathrm{D}_{2}$ was supplied from the feed of the lead column $I$ with a flow rate of $2.0 \mathrm{~L} / \mathrm{min}$. for about 2 hours. Fig. 7 show the HD and $D_{2}$ composition profiles just before and at 5 hours after $D_{2}$ introduction to Column I. Good conformities between GC measurements and steady state 
simulation results in both cases imply that column I has got a steady state within 5 hours. No notable change can be seen except at the top, that is, Column I could tied over the fluctuation of inlet load quickly and dump the fed $D_{2}$ from the top as a light key. On the other hand, we affirmed that Column $\mathrm{H}$ has not established steady state eventually after D2 introduction and the GC measurements have gone off steady state numerical analyses still more. Nevertheless, tritium level of the product off the top has been no more than $0.35 \mathrm{ci} / \mathrm{m}^{3}$ though measured $D_{2}$ concentration in the feed stream increased from $83 \%$ to $98 \%$.

\section{Dynamic analysis}

For further stability and performance data, advancing the former discussions as well, dynamic behavior of the column have to be investigated. The JAERI has developed the dynamic simulation code which adopts an integration algorithm developed by Ballard and Brosilow and deals with a single or two column cascade system ${ }^{11}$. We modified the code for applying it to the existing Iss system with 4 column configuration, and made some trial analyses to obtain preliminary knowledges for dynamic behaviors of the interlinked 4 column system. Fig. 8 and 9 show the transitional compositions at the top of Column I and $\mathrm{H}$ after starting $\mathrm{H}_{2}$ injection at a flow rate of $100 \mathrm{cc} / \mathrm{min}$. The analytical conditions are listed in Table 2. The composition profiles at steady state condition without any impurity addition, where the Column $H$ top flow recycled to the feed internally as shown in Fig. 1 , were given as column initial conditions for the analyses. The results point out the dynamic interactions attribuce to multiple column linkage as noted previously. Column I achieves a steady state condition within 2 hours, whereas the compositions of Column $\mathrm{H}$ do not saturate and vary gradually even after 6 hours. An unique turning point can be seen at the time of ca. 20 minutes on the Column $H$. This momentary less separation of light key would come from a flow path change of the top withdrawal to an external discharging mode. The dynamic interactive factor seem to be significant to evaluate the characteristics of the ISS multicolumn cascade system although the system is in an ideal condition free from physical perturbation.

Presently, a new laser Raman spectroscopic gas analyzer with a 6 Wmax Art laser has been installed at the TSTA. This on-line system analyze ISS sample gas frequently at various points on the columns and enables to chase dynamic behavior of the ISS system with combining dynamic simulation analyses. Recently we carried out the 3 column ISS operation with the Raman gas analyzing system to confirm interfacial functions, availability, intensity and reproductivity of the gas analysis ${ }^{12}$. The new system successfully analyzed continuous flowing sample gas from a tap of ISS every second. The results showed good agreements with those of the existing GC. The GC allows 40 minutes typically for one batch analyzing, while two minutes was enough for the Raman system to obtain steady spectral reproductivety even when switching sampling positions. Fig. 10 gives dynamic transition of Raman spectra at Column $\mathrm{I}$ top after initiating $\mathrm{H}_{2}$ injection. The empirical situations; slow $\mathrm{D}_{2}$ diminution, ascending protium components and emergence of DT, are quite similar to the numerical prediction shown in Fig. 9. However, the observed delay time of one hour till appearances of the above changes is not explainable here unless more internal dynamic information of the column are obtained. An external system 
conductance may possibly concern. The successful demonstrative operation with the new gas analysis system suggests a key to solve the dynamic phenomena and non-linear mechanism within the columns for the multicolunin system and, what's more, a feasibility of feedback control for optimizing performances of the ISS system in future.

\section{CONCIUSION}

(1) The existing ISS system can be used as a three column system which may help in stabilizing the system, and possibly has a flexibility to numerous fusion fuel cycle concepts.

(2) Particular stability improvements appeared on column I. Column I has been fully in steady state condition through the operation and adapted itself quickly to a step change of inlet load.

(3) The GC data of Column $\mathrm{H}$ had poor agreements with numerical predictions in steady state condition. Sensitive dependence of distillation on reflux ratio, hydraulic effects: higher and maldistributed pressure drops along the column, and peculiar dynamic characteristics are suspected as causes.

(4) The combination of the new Raman on-line gas analysis system and the modified dynamic simulation code provide a promising way to search the dynamics and further stability data for the multicolumn cascade system.

(5) Improvement of some instruments is being underway to enhance system stability still more.

\section{AKNONIEDGEMENTS}

The authors would like to acknowledge helpful discussion with Dr. Takumi Hayashi and Mr. Kazuo Hirata (JAERI) and express sincere thanks to Mr. Hirofumi Nakamura (JAERI) for providing valuable data of the latest laser Raman spectroscopic gas analysis system testing.

\section{REFERENCES}

1. J. R. BARTLIT, W. H. DENTON, and R. H. SHERMAN, "Hydrogen Isotope Distillation for the Tritium systems rest Assembly", Proc. 3rd ANS Topl. Mtg. on the Technology of Controlled Nuclear Fusion, Santa Fe, NM, May 9-11, 1978, CONF-780508, Vol. 2, pp. 778 .

2 J. R. BARTLIT, R. H. SHERMAN, R. A. STUTZ and W. H. DENTON, "Hydrogen Isotope Distillation for Fusion Power Reactors", Cryogenics, 19,275 (1979)

3 H. YOSHIDA, H. FUKUI, S. HIRATA, T. YAMANISHI, T. NAITO, J. L. ANDERSON, J. R. BARTLIT, C. R. WALTHERS, R. H. SHERMAN, D. O. COFFIN, R. V. CARLSON, R. S. WILIMS and J. E. NASISE, "TSTA LOOp Operation with 100 Grams-level of Tritium (Full Components Milestone Run in June, 1988), JAERI-M, 88-242(1.988) 
4 J. L. ANDEhJON, J. R. BARTLIT, R. V. CARLSON, D. O. COFFIN, F. A. DAMIANO, R. H. SHERMAN, R. S. WILLMS, H. YOSHIDA, T. YAMANISHI, T. NAITO, S. HIRATA and Y. NARUSE, "Experience of TSTA Milestone Runs with 100 Gram-level Tritium", Fusion Technology, 14, 438(1988)

5 R. H. SHERMAN, J. R. BARTLIT, K. M. GUETZMACHER, H. YOSHIDA, T. YAMANISHI, T. NAITO, S. HIRATA and Y. NARUSE, "Operation of the TSTA Isotope Separation System with 100 Gram Tritium", Fusion Technology, 14, $1273(1988)$

6 K. OKUNO, M. ENOEDA, T. IDE, H. FUKUI, H. YOSHIDA, Y. NARUSES, J. L. ANDERSON, J. R. BARTLIT, R. H. SHERMAN, R. V. CARLSON, D. O. COFFIN and $J$. E. NASISE, "Joint Operation of TSTA under the Collaboration between JAERI and DOE-LANL", JAERI-M, 90-028(1990)

7 Y. NARUSE, K. OKUNO, H. YOSHIDA, S. KONISHI, J. I. ANDERSON and J. R. BARTLIT, "Developments of Tritium Technology for Next-step Fusion Devices under JAERI-DOE (LANL) Collaboration", Journal of Nuclear Science and Technology, 27[12], 1081(1990)

8 T. YAMANISHI, H. YOSHIDA, T. NAITO, S. HIRATA, R. H. SHERMAN and J. R. BARTLIT, "Hydrogen Isotope Separation Study with TSTA Cryogenic Distillation System (Single Column Experiment with D-T System)", JAERIM, 88-253(1988)

9 T. YAMANISHI, H. YOSHIDA, T. NAITO, S. HIRATA and Y. NARUSE, R. H. SHERMAN, J. R. BARTLIT, K. M. GUETZMACHER and J. L. ANDERSON, "Single Column and Two-column H-D-T-Distillation Experiments at TSTA", Fusion Technology, 14, $489(1988)$

10 T. YALANISHI, H. YOSHIDA, T. NAITO, S. HIRATA, R. H. SHERMAN and J. R. BARTLIT, "Hydrogen Isotope separation study with the TSTA Cryogenic Distillation system (Two-column Experiment with $H-D-T$ System)", JAERI-M, 88-253(1988)

11 M. KINOSHITA, "Drastic Reduction of Computing Time in Dynamic Simulation for Hydrogen Isotope Distillation Columns", Fusion Technology, 9, 492(1986)

12 S. O'HIRA, H. NAYAMURA, S. KONISHI, T. HAYASHI, K. OKUNO, Y. NARUSE, R. H. SHERMAN, D. J. TAYLOR, M. A. KING, J. R. BARTLIT and J. L. AAANDERSON, "On-line Tritium Process Gas Analysis by Laser Raman Spectroscopy at TSTA", Fusion Technology, in press. 


\section{Figure captions}

FIGURE 1. SCHEMATIC DIAGRAM OF THE ISOTOPE SEPARATION SYSTEM

FIFURE 2. RELATION BETWEEN PRESSURE DROP ACROSS COLUMN AND VAPOR VELOCITY

FIGURE 3. COMPARISON OF GC MEASUREMENTS WITH NUMERICAL STEADY STATE ANALYSES FOR COLUMN I

FIGURE 4. COMPARISON OF THE GC MEASUREMENTS WITH NUMERICAL STEADY STATE ANALYSES FOR COLUMN H

FIGURE 5. EFFECT OF THE TOP FLOW CHANGE ON SEPARATION CHARACTERISTICS OF COLUMN H

FIGURE 6. EFFECT OF REFLUX RATIO ON SEPARATION CHARACTERISTICS OF COLUMN H

FIGURE 7. RESPONCE OF COLUMN I AGAINST A STEP ADDITION OF D2 TO THE FEED

FIGURE 8. A DYNAMIC SIMULATION RESULT FOR COLUMN I

FIGURE 9. A DYNAMIC SIMULATION RESUI.T FOR COLUMN H

FIGURE 8. DYNAMIC CHANGE OF RAMAN SPECTRA AT THE TOP OF COLUMN I 
Table 1 Nominal Conditions and Column Dimensions for Operation

\begin{tabular}{|c|c|c|c|c|}
\hline & COLUMN & COLUMN H & COLUMN D & COLUMN T \\
\hline TOP FLOW, cc/min & 1300 & 100,260 & 4750 & - \\
\hline FEED FLOW, cc/min & 6000 & 5000 & 5000 & 4700 \\
\hline $\begin{array}{c}\text { BOTTOM FLOW, } \\
\text { cc/min }\end{array}$ & 4700 & $5000(3700)$ & 250 & - \\
\hline PRESSURE, T orr & 860 & 800 & 700 & - \\
\hline REBOILER POWER, w & 35 & 20 & 10 & - \\
\hline PACKED HEIGHT, m & 4.11 & 4.06 & 4.11 & 3.20 \\
\hline IN-DIAMETER, mm & 29.0 & 19.0 & 38.0 & 23.2 \\
\hline
\end{tabular}


Table 2 Conditions for Dynamic Analysis

\begin{tabular}{|c|c|c|c|c|}
\hline & COLUMN & COLUMN H & COLUMN D & COLUMN T \\
\hline TOP FLOW, cc/min & 1300 & 100 & 4750 & 4000 \\
\hline FEED FLOW, cc/min & 6000 & $5000(3700)$ & 5000 & 4700 \\
\hline BOTTOM FLOW, cc/min & 4700 & 5000 & 250 & 700 \\
\hline PRESSURE, Torr & 860 & 800 & 700 & 700 \\
\hline REBOILER POWER, W & 35 & 20 & 10 & 15 \\
\hline
\end{tabular}




\section{Figure captions}

FIGURE 1. SCHEMATIC DIAGRAM OF THE ISOTOPE SEPARATION SYSTEM

FIFURE 2. RELATION BETWEEN PRESSURE DROP ACROSS COLUMN AND VAPOR VELOCITY

FIGURE 3. COMPARISON OF GC MEASUREMENTS WITH NUMERICAL STEADY STATE ANALYSES FOR COLUMN I

FIGURE 4. COMPARISON OF THE GC MEASUREMENTS WITH NUMERICAL STEADY STATE ANALYSES FOR COLUMN H

FIGURE 5. EFFECT OF THE TOP FLOW CHANGE ON SEPARATION CHARACTERISTICS OF COLUMN H

FIGURE 6. EFFECT OF REFLUX RATIO ON SEPARATION CHARACTERISTICS OF COLUMN H

FIGURE 7. RESPONCE OF COLUMN I AGAINST A STEP ADDITION OF D2 TO THE FEED

FIGURE 8. A DYNAMIC SIMULATION RESULT FOR COLUMN I

FIGURE 9. A DYMAMIC SIMULATION RESULT FOR COLUMN H

FIGURE 8. DYNAMTC CHANGE OF RAMAN SPECTRA AT THE TOP OF COLUMN I 


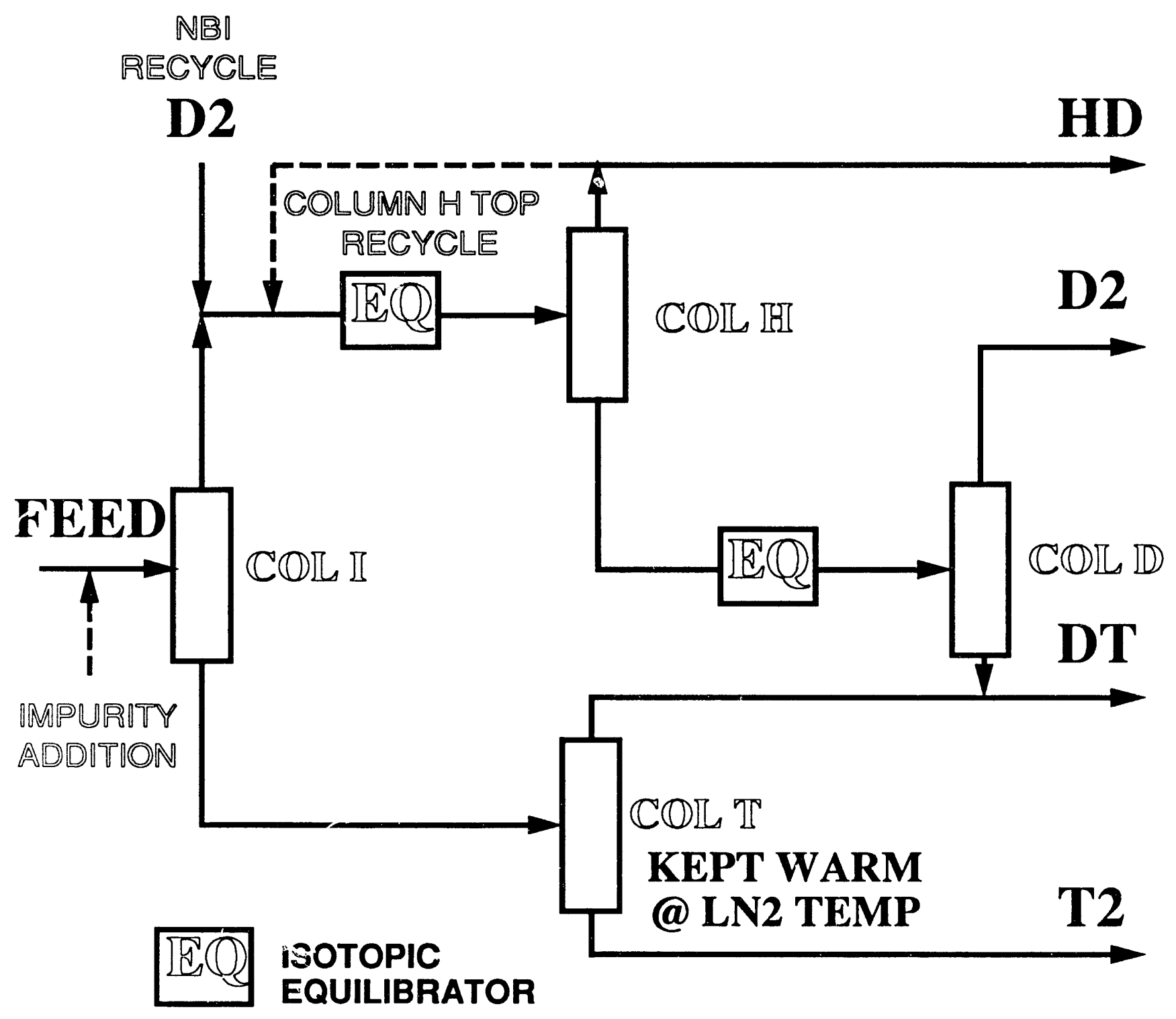

Fig. 1 Schematic Diagram of the Isotope Separation System 


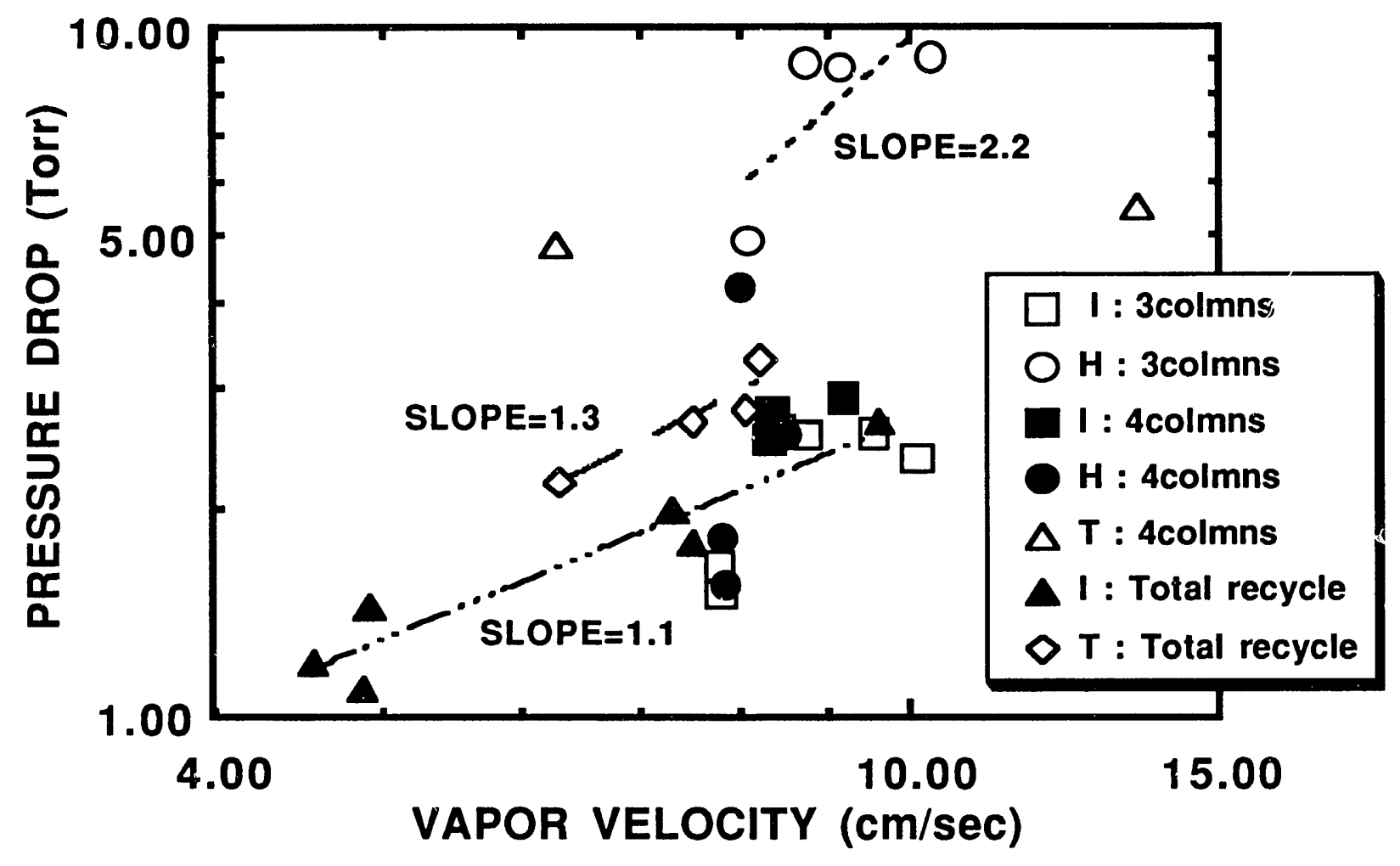

Fig. 2 


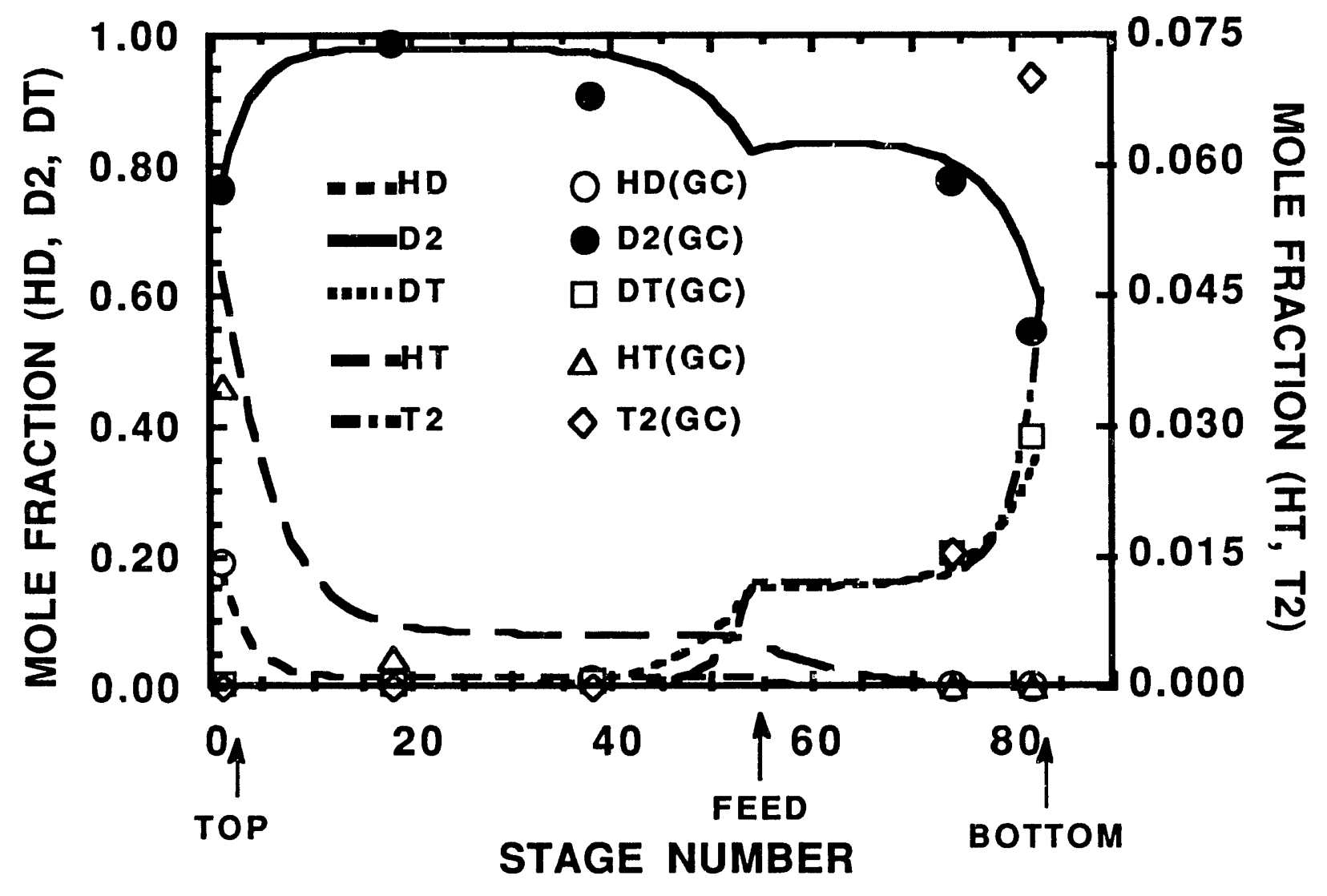

Fig. 3 


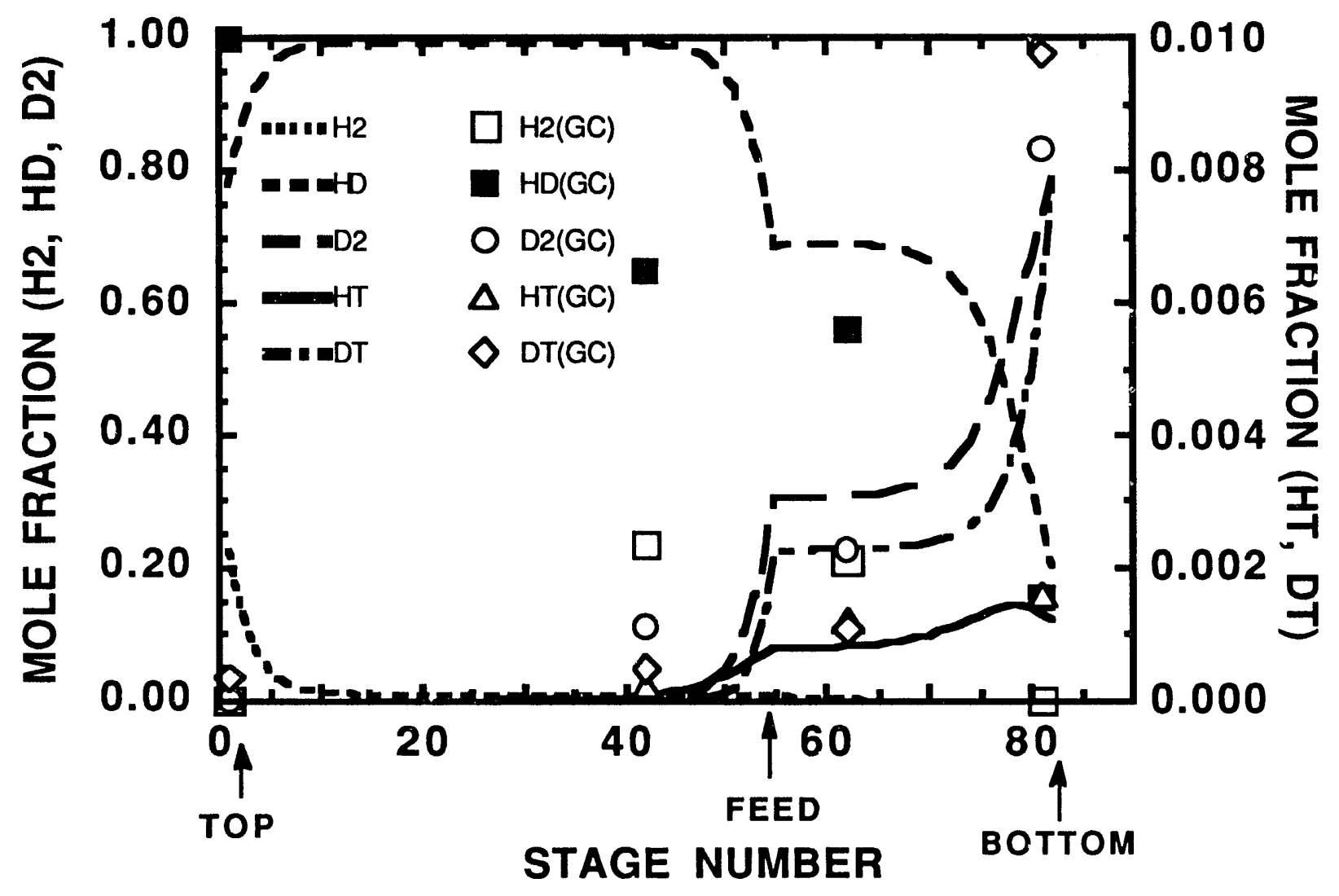

Fig. 4 


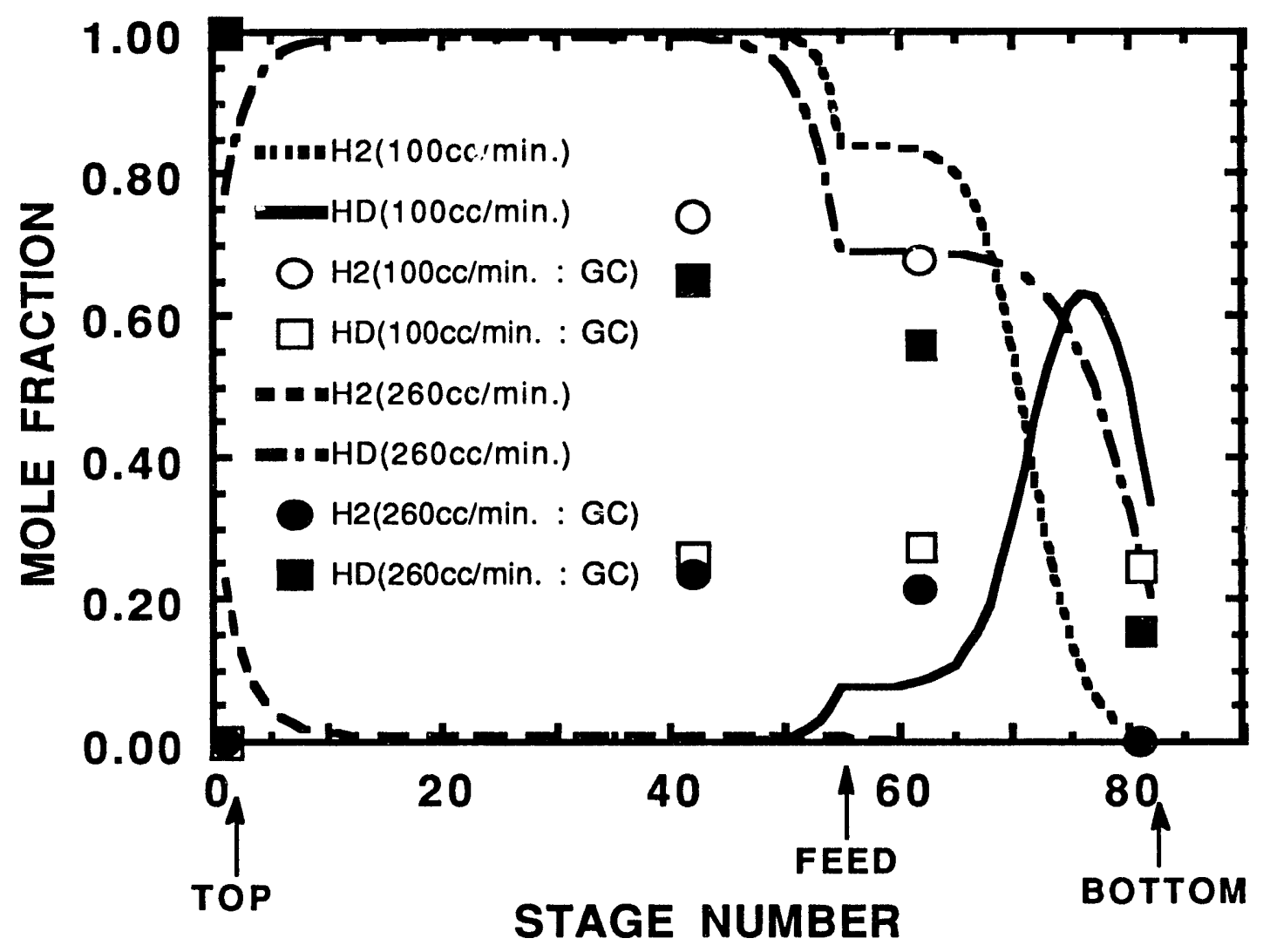

Fig. 5 


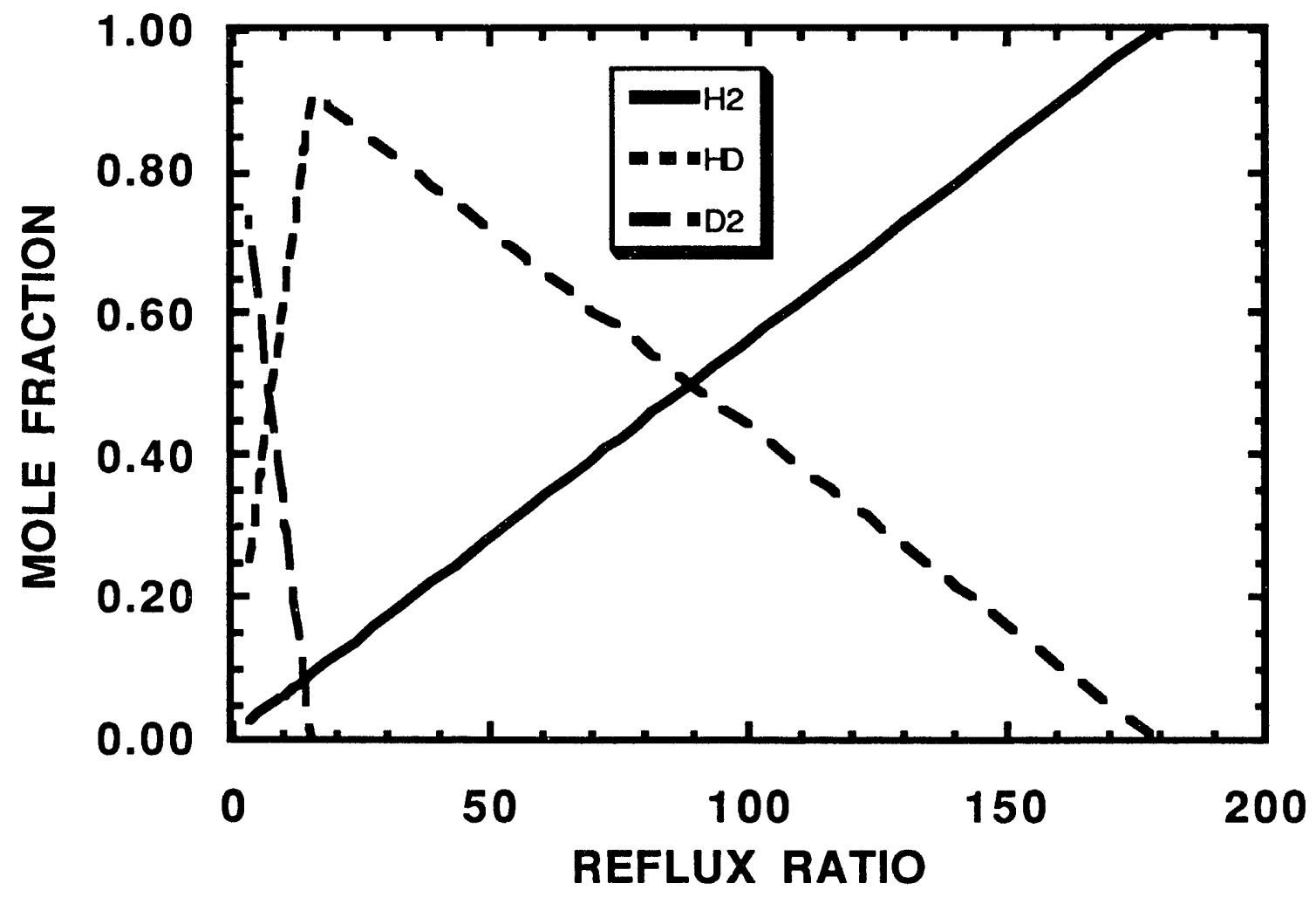

Fig. 6 


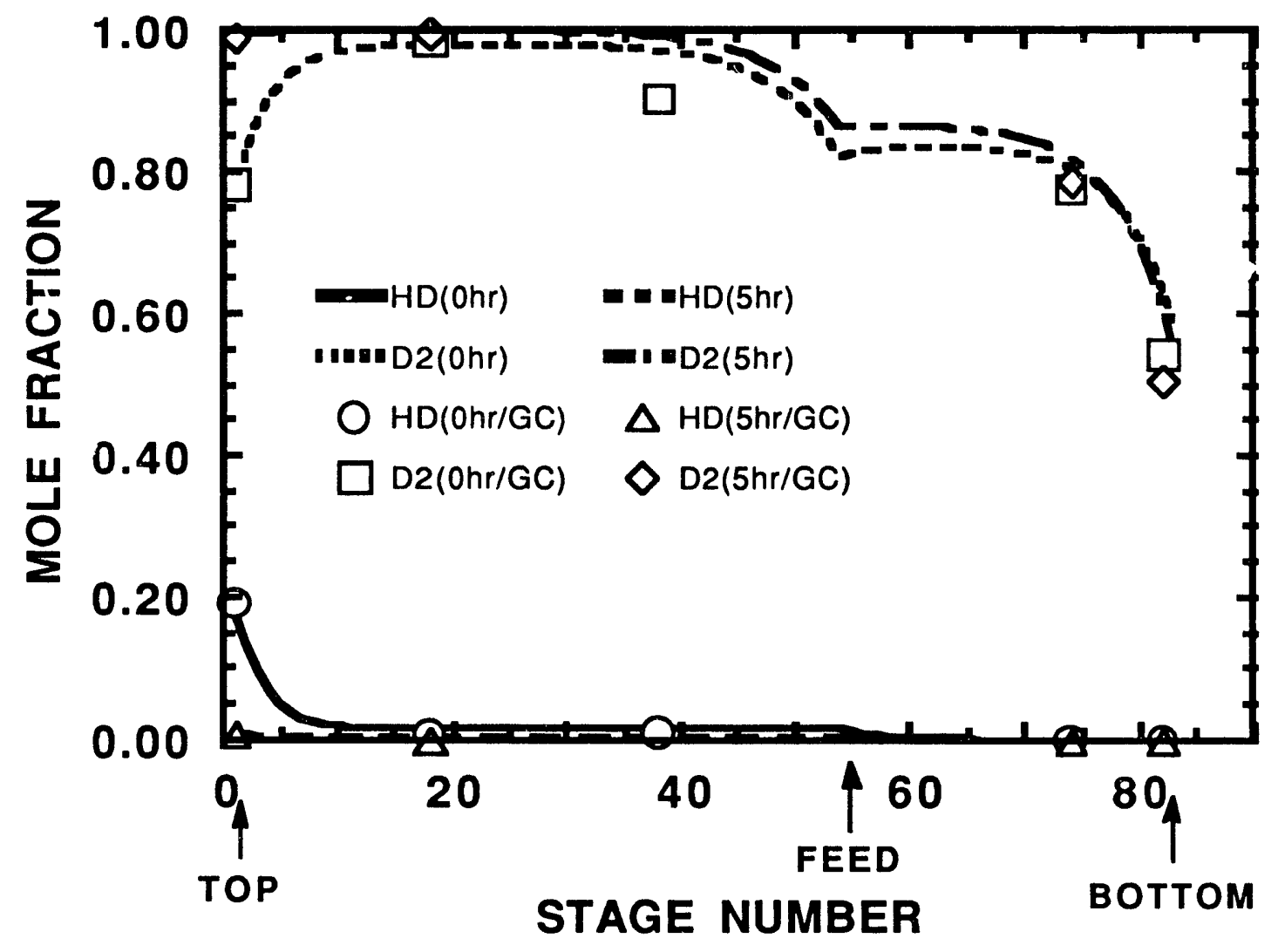

Fig. 7 


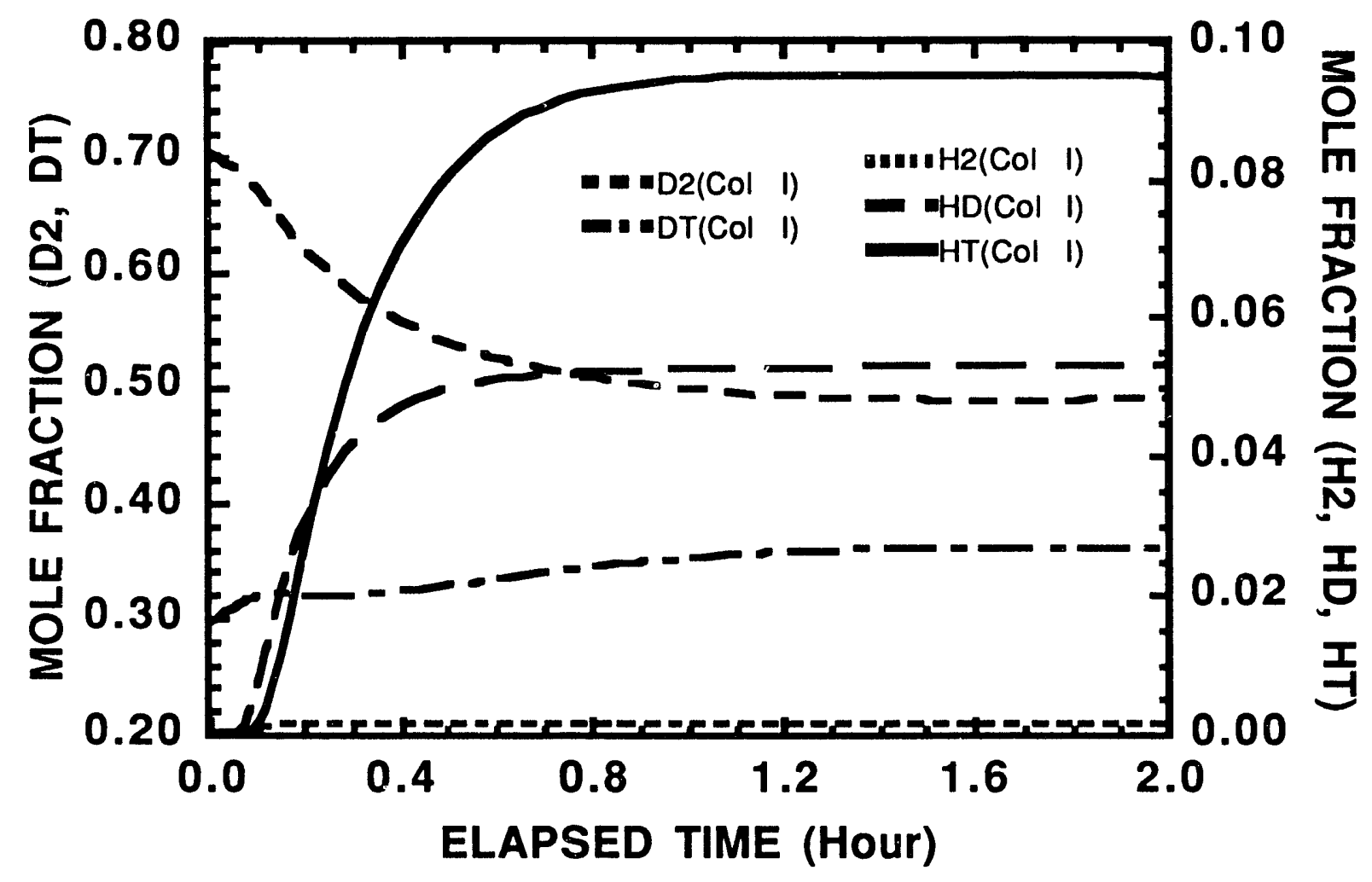

Fig. 8 


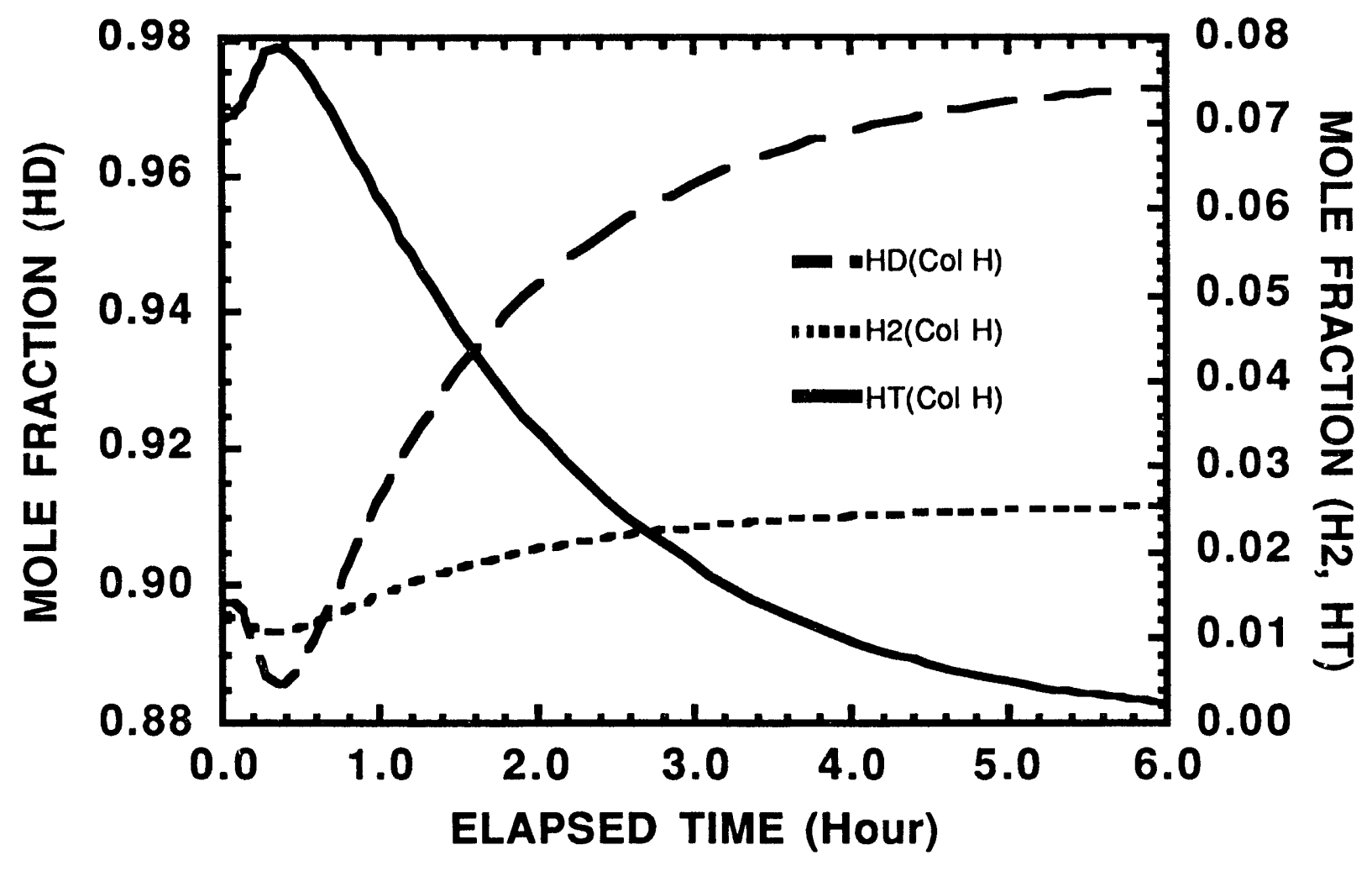

Fig. 9 


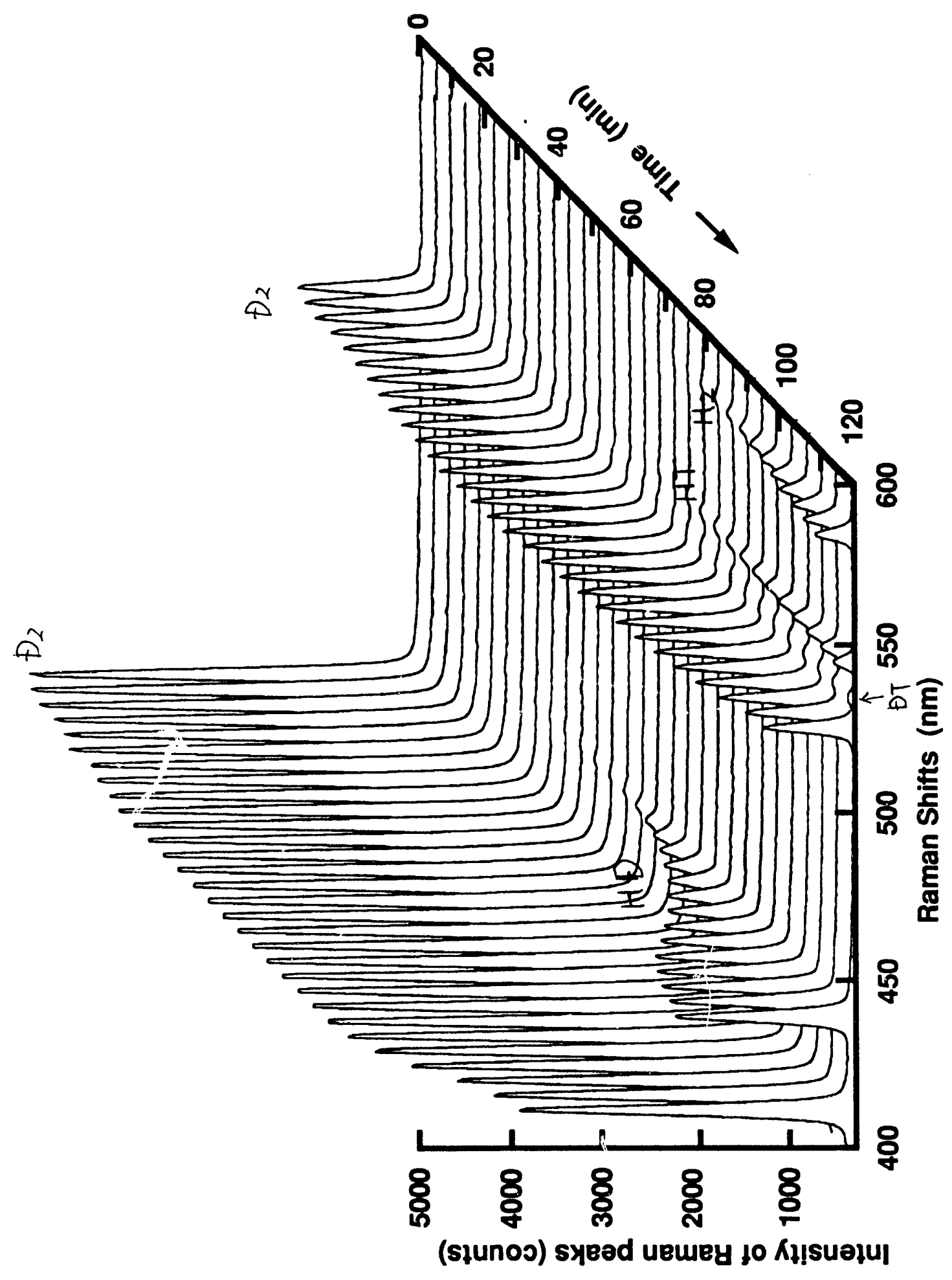

Fig. 10 

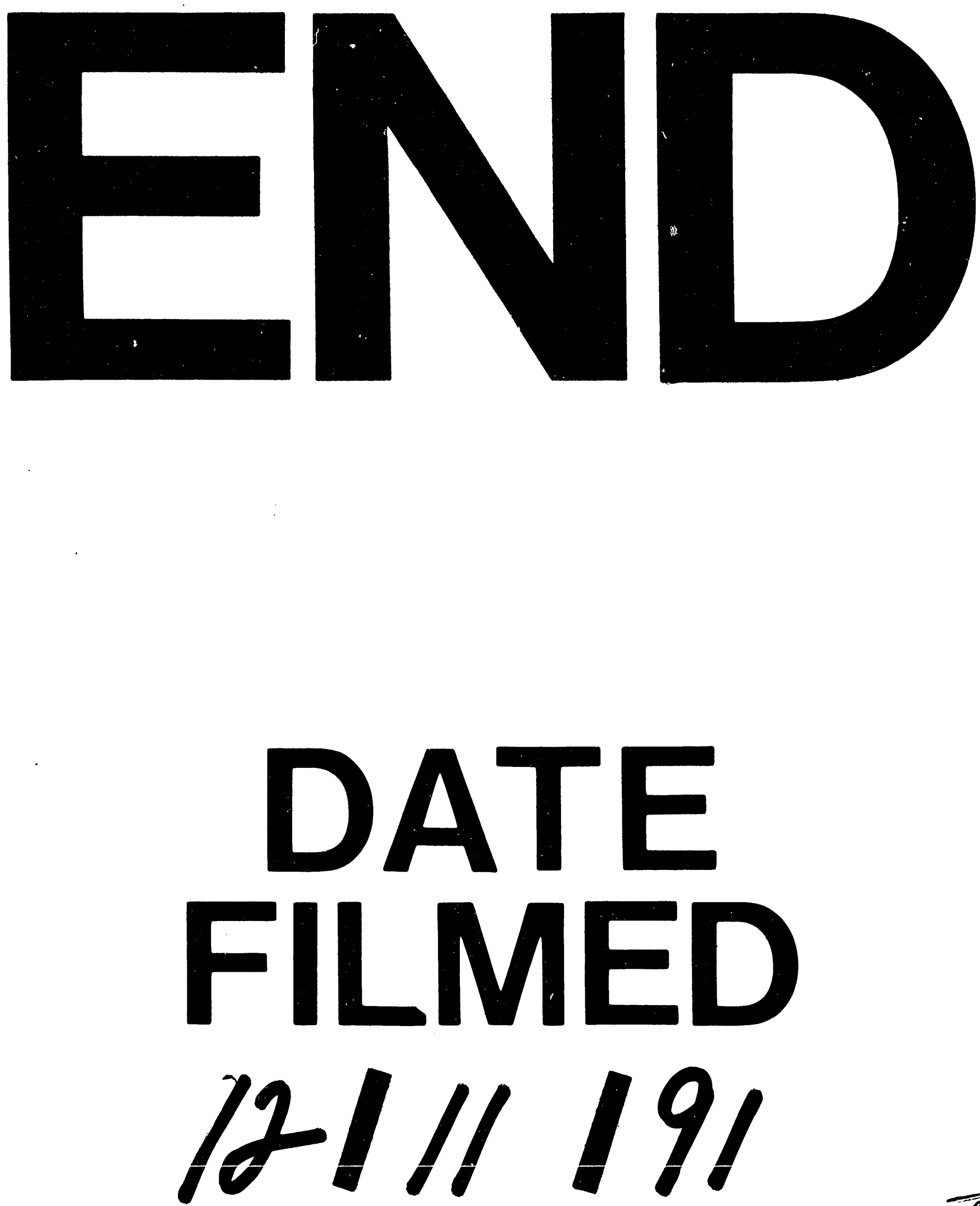
